LINGUA, Vol. 16, No. 1, Maret 2019

p ISSN: 1979 9411; e ISSN: 2442 238X

Http://lingua.pusatbahasa.or.id; Email: presslingua@gmail.com

Center of Language and Cultural Studies, Surakarta, Indonesia

Fitriyani, Iin; Wilian, Sudirman \& Yusra, Kamaludin. 2019. Ekspresi Bahasa Indonesia Tulis berdasarkan Gender pada Media Facebook.

Lingua (2019), 16(1): 137 156. DOI: 10.30957/lingua.v16i1.581.

\title{
EKSPRESI BAHASA INDONESIA TULIS BERDASARKAN GENDER PADA MEDIA FACEBOOK
}

\author{
Iin Fitriyani, Sudirman Wilian \& Kamaludin Yusra \\ Magister Pendidikan Bahasa Indonesia Universitas Mataram \\ Jalan Majapahit No. 6 Mataram Nusa Tenggara Barat \\ Corresponding E-mail: iinfitriyani3@gmail.com
}

\begin{abstract}
This study aims to determine differences in the choice of topics of conversation between men and women on Facebook media. This study was a qualitative in nature, examining corpus of facebookers available in an internet. The process of data collection was done by referring to the record and documentation method. In the analysis process, data were classified and analyzed based on Tuncay's theory (2006) in determining the theme of masculinity and Cholik (2016) theory in determining the theme of femininity. The results showed that male users tended to upload themes to show their masculinity such as physical strength, altruism, women and sex, love and family, pleasure or fun, leadership, outdoor activities, as well as spirituality and morality, while female users tended to upload theme to reflect the feminine side, such as cooking, parenting, beauty, traveling, hobbies, and fashion.
\end{abstract}

Keywords: gender, media facebook, status facebook.

DOI: $10.30957 /$ lingua.v16i1.581.

\section{PENDAhULUAN}

Penelitian ini mengkaji ekspresi dalam status facebook yang digunakan oleh facebooker perempuan dan facebooker laki-laki. Fokus kajian ialah bagaimana ekspresi maskulitas dan feminitas terungkapo dalam ujaran dan komentar yang tertuang dalam facebook. Sebagai media sosial, facebook telah digunakan secara bebas oleh masyarakat dalam berinteraksi. Kebebasan tersebut telah diperoleh oleh segala lapisan pengguna media sosial. Namun, kebebasan berinteraksi tersebut tidak sejalan dengan pengendalian dan penguasaan bahasa komunikasi yang santun dan tidak melanggar norma.

Penelitian ini didasari pada kenyataan bahwa perkembangan teknologi informasi yang begitu marak, berimplikasi signifikan terhadap paradigma komunikasi, media komunikasi, dan cara bagaimana komunikasi itu dimanfaatkan dengan perantaraan media. Penggunaan bahasa dalam berbagai penggunaan alat komunikasi seperti handphone, facebook, blog, website, dapat menggambarkan identitas diri pengguna bahasa tersebut. Fenomena penggunaan bahasa (terutama tulisan) yang berwujud komentar-komentar yang terdapat di dalam bahasa facebook, twitter tentunya mencerminkan pikiran, perilaku, serta sikap pengguna bahasa tersebut. 
LINGUA, Vol. 16, No. 1, Maret 2019

p ISSN: 1979 9411; e ISSN: 2442 238X

Http://lingua.pusatbahasa.or.id; Email: presslingua@gmail.com

Center of Language and Cultural Studies, Surakarta, Indonesia

Fitriyani, Iin; Wilian, Sudirman \& Yusra, Kamaludin. 2019. Ekspresi Bahasa Indonesia Tulis berdasarkan Gender pada Media Facebook.

Lingua (2019), 16(1): 137 156. DOI: 10.30957/lingua.v16i1.581.

Jejaring sosial yang paling banyak diminati saatini adalah facebook. Salah satu fitur facebook yang diperbaharui setiap saat oleh para penggunanya adalah status. Melalui status, para pengguna facebook dapat menginformasikan segala aktivitas yang mereka lakukan. Selain itu, mereka juga dapat saling berkomentar atau menanggapi status terbaru dari sesama pengguna facebook. Status facebook merupakan transformasi bahasa lisan ke bahasa tulis. Di dalam facebook sering dijumpai status yang berisi ekspresi halus sampai yang sangat kasar bahasa pemilik status. Laki-laki maupun perempuan sering menunjukkan ekspresi tersebut dalam bentuk sapaan, rasa syukur, kemarahan, rasa cinta, rasa benci, maupun kesedihan. Dalam batas tertentu, ekspresi dalam status tidak lagi memperhatikan norma dan tata nilai sosial, seperti dikutip dalam kutipan 0\#.

0\# Laki-laki: "Anjing loe cma gra" duit tai ajak..makan tu duit tai..! anjing.."

Perempuan: "Aduh mantan2 kasian deh aku sama km mau manasin ak

ma cewe kaya gitu aduh gak mempan ya baru penampilanya kaya gitu biar dia cantik bageikan bidadari pun aku gak sakit hati karna $\mathrm{km}$ dah bukan siapa2 aku lagi ok, jadi gak penting buat ak n gak ngurusin jangan jadi kan cewe lain jadi korban mu karna cinta kasian tau nih cewe"

Kutipan 0\# tergolong bentuk ekspresi kasar pengungkapan perasaan penutur dalam mengungkapkan rasa kesal atau marah. Baik laki-laki maupun perempuan dalam pengungkapan ekspresi bisa dilihat perbedaannya, seperti facebooker laki-laki dalam mengekspresikan perasaannya menggunakan swear words atau kata makian untuk memberikan penekanan pada tuturan dan menjadi cara untuk menghina seseorang. Hal ini berdasarkan teori Coates dalam fitur bahasa laki-laki dalam swearing and taboo language. Sedangkan dalam status facebooker perempuan menggunakan avoidance swear word yaitu menghindari bentuk kata-kata kasar untuk menghina seseorang. Hal ini berdasarkan teori Lakoff dalam fitur bahasa perempuan.

Salah satu fungsi bahasa adalah sebagai alat penyampaian informasi yang disampaikan melalui media massa, seperti media cetak, media elektronik, dan media siber (cyber media). Media siber yaitu segala jenis atau format media yang hanya bisa diakses melalui internet, meliputi: email, website, blog, dan media sosial. Adapun isinya, yaitu teks, foto, video, dan suara. Dalam media siber, khususnya jejaring sosial lebih banyak diminati oleh semua kalangan. Jejaring sosial tersebut berfungsi sebagai media komunikasi, menjalin pertemanan, bertukar pikiran dan informasi bahkan berbisnis. Beberapa situs jejaring sosial yang paling banyak digunakan masyarakat untuk menyampaikan informasi adalah facebook, twitter, whatsapp, instagram, dan sebagainya. Jejaring sosial yang paling banyak diminati saat ini adalah facebook. Salah satu fitur facebook yang diperbaharui setiap saat oleh para penggunanya adalah status. Status facebook merupakan transformasi bahasa lisan ke bahasa tulis. Penelitian ini secara khusus menggali bagaimana ekspresi dalam statius yang ditulis oleh facebooker perempuan dan facebooker laki-laki. 
LINGUA, Vol. 16, No. 1, Maret 2019

p ISSN: 1979 9411; e ISSN: 2442 238X

Http://lingua.pusatbahasa.or.id; Email: presslingua@gmail.com

Center of Language and Cultural Studies, Surakarta, Indonesia

Fitriyani, Iin; Wilian, Sudirman \& Yusra, Kamaludin. 2019. Ekspresi Bahasa Indonesia Tulis berdasarkan Gender pada Media Facebook.

Lingua (2019), 16(1): 137 156. DOI: 10.30957/lingua.v16i1.581.

Penelitian mengenai gender oleh Sri Yuliani (2013) berjudul "Perbedaan Gender dalam Penguasaan Bahasa Dipandang dari Perspektif Psikologi Pendidikan" menjelaskan terdapat beberapa perbedaan penguasaan bahasa baik laki-laki dan perempuan dilihat dari aspek pendidikan keluarga, superioritas, dan sosio-kultural. Aspek pendidikan keluarga, perbedaan pola perlakuan dalam pendidikan keluarga yang ditunjukkan orang tua kepada anak-anaknya menjadi cetakan pertama yang diterima anak laki-laki dan anak perempuan, sehingga dari hal tersebut membuat kedua gender menguasai pola bahasa yang berbeda. Selanjutnya, superioritas, perbedaan kelebihan yang ditunjukkan oleh gender laki-laki dan perempuan adalah laki-laki lebih senang berbicara di depan umum, menegosiasi status, berbicara satu persatu, dan berbicara secara asimetris, sedangkan perempuan memiliki ciri-ciri bicara lebih banyak, berbicara dalam konteks pribadi dan tertutup, membuat suatu hubungan, dan berbicara secara simetris. Adapun sosio-kultural, dalam perbedaan status laki-laki dan perempuan ditunjukkan melalui penempatan pembagian pekerjaan di masyarakat seperti gender laki-laki lebih banyak dilibatkan di luar ruangan sementara gender perempuan lebih banyak dilibatkan di dalam ruangan.

Penelitian ini juga menemukan bahwa perbedaan posisi ditunjukkan dengan adanya pemberian tanggung jawab biasanya gender laki-laki merupakan pemimpin dalam suatu kegiatan masyarakat dibandingkan gender perempuan yang hanya sebagai pendukung, sementara perbedaan peran dalam masyarakat dilihat dari sisi gender lakilaki dan gender perempuan dengan peran masing-masing untuk kepentingan masyarakat.

Evawani Elysa Lubis (2014) menulis "Potret Media Sosial dan Perempuan" untuk mendeskripsikan keberadaan media sosial yang telah menjadi media yang sangat mempengaruhi kehidupan manusia terutama perempuan. Hasil penelitian menunjukkan bahwa perempuan adalah pengguna media sosial yang paling dominan. Penyebabnya ialah karakteristik media sosial yang partisipatif, terbuka, percakapan, komunitas dan keterhubungan memberikan peluang kepada perempuan untuk dapat menyalurkan aspirasi, perasaan maupun idenya kepada teman-teman, kolega maupun saudaranya. Dalam media meanstream perempuan sering dijadikan sebagai objek kepentingan, tetapi pada media sosial perempuan lebih dapat menjadi dirinya sendiri. Melalui media sosial ini perempuan dapat lebih aktif berperan di dalam dunia bisnis dengan membangun usahanya sendiri; di bidang politik perempuan lebih bisa menyalurkan aspirasinya untuk mewakili kepentingan perempuan; dan di bidang psikologi perempuan menggunakan media sosial untuk mengurangi stress yang dirasakan termasuk dengan teknologi komunikasi lainnya.

Penelitian Juliano (2015) berjudul "Komunikasi dan Gender: Perbandingan Gaya Komunikasi dalam Budaya Maskulin dan Feminim" menjelaskan bahwa adanya pengaruh konsep gender dalam gaya komunikasi laki-laki dan perempuan menunjukkan terdapat perbedaan gaya komunikasi dalam budaya maskulin dan feminim berdasarkan pengalaman dan pengamatan yang dilakukan. Merujuk pada Deficit Theory (Two Culture) (Maltz and Borker), Genderlect Styles Theory (Deborah Tannen), dan Man Are From Mars Vs Woman Are From Venus (John Gray) Juliano memaparkan bahwa 
LINGUA, Vol. 16, No. 1, Maret 2019

p ISSN: 1979 9411; e ISSN: 2442 238X

Http://lingua.pusatbahasa.or.id; Email: presslingua@gmail.com

Center of Language and Cultural Studies, Surakarta, Indonesia

Fitriyani, Iin; Wilian, Sudirman \& Yusra, Kamaludin. 2019. Ekspresi Bahasa Indonesia Tulis berdasarkan Gender pada Media Facebook.

Lingua (2019), 16(1): 137 156. DOI: 10.30957/lingua.v16i1.581.

peran gender tergambarkan melalui adanya seksis (diskriminasi buruk kepada seseorang berdasarkan bias gender) dalam bahasa laki-laki dan perempuan dari beberapa budaya tertentu. Juliano juga menemukan bahwa terdapat perbedaan gaya komunikasi antara dua budaya yakni budaya maskulin dan budaya feminim, berdasarkan beberapa katagori, yaitu: saat berbicara, pemilihan topik pembicaraan, penggunaan kata dan kalimat tanya, menggunakan cerita dan guyonan. Berdasarkan latar belakang di atas, penelitian ini, dipandu dengan tiga pertanyaan penelitian berikut:

1) Jenis topik apa saja yang digunakan oleh facebooker laki laki dan facebooker perempuan dalam menuliskan status di facebook?

2) Apakah ada perbedaan cara pengungkapan topik tertentu antara laki-laki dan perempuan?

3) Apakah ada perbedaan cara pengungkapan ketika berkomunikasi dengan teman sesama jenis atau lawan jenis melalui media facebook?

\section{LANDASAN TEORI}

Secara teoritis penelitian ini dilandasi oleh teori gender dan sexist language. Istilah "gender" bukanlah sinonim dari "jenis kelamin" (sex). Seks mengacu pada perbedaan biologis yang merupakan pemberian dari Tuhan, sedangkan gender merupakan istilah yang digunakan untuk menggambarkan kategori-kategori dan konstruksi yang terbentuk secara sosial budaya berdasarkan jenis kelamin. Gender bukanlah bawaan individu dari lahir dan bukan sesuatu yang kita punya melainkan sesuatu yang kita lakukan. Gender merupakan bentukan dari kebudayaan, gender merepresentasikan suatu pembagian penting dalam masyarakat bahwa seseorang itu termasuk laki-laki atau perempuan bukanlah sebuah faktanya biologis, melainkan sebuah kontruksi masyarakat dan kebudayaan. Dalam gender membahas mengenai maskulin dan feminism. Maskulinitas merupakan sebuah pengakuan yang didasarkan pada konstruksi sosial yang dibentuk oleh budaya masyarakat dalam kehidupan sosial.

Lakoff (1975) membuat beberapa perbedaan ciri bahasa yang digunakan oleh laki-laki dan perempuan. Penggunaan bahasa tidak dapat dilepaskan dari stereotipe seseorang, sehingga dalam banyak konteks, dunia terbagi dalam dua gagasan yang bersifat seksualitas. Seorang perempuan akan lebih memposisikan penggunaan bahasa yang lebih feminim sedangkan laki-laki lebih menggunakan bahasa secara maskulin. Jika ditinjau secara biologis, laki-laki dan perempuan memang nyata-nyata berbeda dan sosialisasi yang dialaminya pun berbeda. Adapun perbedaan laki-laki dan perempuan menurut Shaevitz (1989) dalam Endriastuti (2014) sebagai berikut:

a. Laki-laki lebih agresif daripada perempuan, cenderung lebih suka bersaing, lebih mudah marah dan mendominasi.

b. Laki-laki kurang memiliki hasrat untuk merawat.

c. Harga diri seorang laki-laki lebih dikaitkan pada pekerjaan. Sedangkan perempuan mengalami kepuasan hidup bila ia berhasil dalam hubungannya dengan sesama.

d. Secara verbal, laki-laki kurang ekspresif daripada perempuan, ia lebih sukar mengungkapkan perasaan. 
LINGUA, Vol. 16, No. 1, Maret 2019

p ISSN: 1979 9411; e ISSN: 2442 238X

Http://lingua.pusatbahasa.or.id; Email:presslingua@gmail.com

Center of Language and Cultural Studies, Surakarta, Indonesia

Fitriyani, Iin; Wilian, Sudirman \& Yusra, Kamaludin. 2019. Ekspresi Bahasa Indonesia Tulis berdasarkan Gender pada Media Facebook.

Lingua (2019), 16(1): 137 156. DOI: 10.30957/lingua.v16i1.581.

e. Laki-laki memiliki kebutuhan lebih besar terhadap kekuasaan. Laki-laki tumbuh dengan permainan yang memerankan kekuasaan, jadi ada kebiasaan untuk mengagumi tokoh-tokoh yang berada dalam posisi pemimpin atau penguasa.

f. Terhadap perkawinannya, laki-laki lebih bergantung dan lebih peka, ia menyukai dukungan emosional dari pasangan.

g. Kebanyakan laki-laki sering berorientasi makro daripada mikro, ia akan menyelesaikan tanggung jawab dengan caranya sendiri.

Dapat disimpulkan bahwa dalam pemahaman masyarakat umum istilah maskulinitas erat hubungannya dengan aspek kekuasaan kejantanan, keperkasaan, kewibawaan, dan sifat jagoan sebagai identitas laki-laki. Tabel 1 dan tabel 2 menunjukkan tema maskulinitas darti Tuncay (2006) dikutip Endriastuti (2014), yang terdiri dari 2 kelompok: maskulinitas inti (core theme of masculinity) dan maskulinitas tambahan (additional theme ofmasculinity).

Tabel 1: Core Theme of Masculinity

\begin{tabular}{|l|l|}
\hline \multicolumn{2}{|c|}{ THEME IN TEXT } \\
\hline Appearance & \multicolumn{1}{c|}{ Brief Decription } \\
\hline Family love & Importance of being physically attractive \\
\hline Leadership respect & Centrality of family, love, and children \\
\hline Money success & Nations of leadership, respect, and power \\
\hline Women sex & Desire to be successful and own material goods \\
\hline
\end{tabular}

Tabel 2: Additional Theme of Masculinity

\begin{tabular}{|l|l|}
\hline \multicolumn{2}{|c|}{ THEME IN TEXT } \\
\hline Adventure outdoor & \multicolumn{1}{c|}{ Brief Decription } \\
\hline Altruism & $\begin{array}{l}\text { Desire to engage in thrilling activites, usually out } \\
\text { in nature }\end{array}$ \\
\hline Fun & $\begin{array}{l}\text { Notions to greater good, giving back to the } \\
\text { community, service to community }\end{array}$ \\
\hline Knowledge & Desire to engage hedonistic activity \\
\hline Spirituality morality & Quest for learning, intellect \\
\hline Strength & Nations of God, religious or moral value \\
\hline
\end{tabular}

Teori Tuncay tersebut, dalam penelitian ini dicari relasinya dengan representasi maskulinitas yang tergambar dalam media sosial khususnya status facebook. Feminitas dan kebudayaam telah menanamkan pola pikir yang kuat bahwasanya perempuan berkedudukan lebih rendah ketimbang laki-laki, perempuan dianggap sebagai kaum yang lemah dan tersisih sehingga sebagian besar keberadaannya tidak dianggap penting. Pemakaian bahasa juga telah terpengaruh oleh adanya gender.

Menurut Cholik (2016) terdapat beberapa topik atau tema yang sering ditulis oleh perempuan di media online, yaitu: 
LINGUA, Vol. 16, No. 1, Maret 2019

p ISSN: 1979 9411; e ISSN: 2442 238X

Http://lingua.pusatbahasa.or.id; Email: presslingua@gmail.com

Center of Language and Cultural Studies, Surakarta, Indonesia

Fitriyani, Iin; Wilian, Sudirman \& Yusra, Kamaludin. 2019. Ekspresi Bahasa Indonesia Tulis berdasarkan Gender pada Media Facebook.

Lingua (2019), 16(1): 137 156. DOI: 10.30957/lingua.v16i1.581.

a. Kuliner, karena sesuai kodratnya kaum perempuan pada umumnya suka memasak atau pamer makanannya.

b. Kecantikan, tampilan fisik yang cantik merupakan bagian penting dalam menunjukkan feminitasnya untuk menarik perhatian lawan jenis.

c. Fashion, perkembangan busana perempuan dan aksesorisnya menjadi topik yang menarik untuk dibahas, bahkan banyak bermunculan status mengenai fashion di online shopping.

d. Parenting, cakupan tema ini sangat luas karena ini menyangkut kegiatan sejak perempuan hamil hingga anak-anak dewasa, serta hubungannya dengan keluarga dan orangtua.

e. Traveling, kaum perempuan yang masih single maupun sudah berkeluarga pada umumnya menyukai traveling, piknik, atau rekreasi. Kegiatan ini memang penting setelah mereka sibuk atau bosan dengan pekerjaannya.

f. Hobi, perempuan biasanya mengunggah hal-hal yang berhubungan dengan hobinya.

Berdasarkan fenomena ekspresi bahasa di atas, peneliti memilih objek penelitian ini dengan beberapa alasan. Pertama, ekspresi bahasa merupakan cara menyatakan, mengungkapkan, atau memberitahukan sesuatu yang dirasakan oleh penutur. Kedua, status facebook merupakan sarana bagi masyarakat untuk mengekspresikan pikiran dan perasaannya melalui media tulisan secara lebih terbuka. Melalui facebook pengguna mendapat kebebasan dalam mengungkapkan beragam hal dengan cara yang mudah dan unik. Akan tetapi, di dalam pengungkapan tersebut seringkali ditemukan adanya perbedaan ekspresi antara laki-laki dan perempuan. Oleh karena itu, peenlitian dilalkukan untuk mengemukakan sejauh mana perbedaan ekspresi bahasa yang dinyatakan oleh laki-laki dan perempuan dalam media facebook.

\section{METODE}

Penelitian ini menggunakan ancangan penelitian deskriptif kualitatif, untuk mendeskripsikan bagaimana pengekspresian bahasa laki-laki maupun perempuan dalam media sosial facebook. Data-data yang diperoleh berupa korpus kumpulan status dalam facebook berupa ujaran, kata dan kalimat (Moleong, 2013:4). Data dikumpulkan menggunakan teknik simak dan dokumentasi. Metode simak adalah teknik memperoleh data dengan cara menyimak penggunaan bahasa (Mahsun, 2007:92). Penelitian ini menggunakan metode simak dengan teknik lanjutan simak bebas libat cakap, maksudnya peneliti melakukan pengamatan dengan cara menyimak teks-teks status yang diunggah oleh para pengguna facebook tersebut dalam status. Metode simak dalam penelitian ini digunakan dengan cara mencatat data berdasarkan gender yang terdapat dalam media facebook. Kedua metode dokumentasi (Sugiyono, 2012:240) merupakan catatan peristiwa yang sudah berlalu. Jadi, metode dokumentasi merupakan pengumpulan data dengan menggunakan catatan peristiwa terdahulu yang berbentuk tulisan atau gambar-gambar dari seseorang. Metode dokumentasi yang digunakan dalam penelitian ini ialah yaitu dengan cara menggunakan foto yang dapat menunjukkan 
LINGUA, Vol. 16, No. 1, Maret 2019

p ISSN: 1979 9411; e ISSN: 2442 238X

Http://lingua.pusatbahasa.or.id; Email: presslingua@gmail.com

Center of Language and Cultural Studies, Surakarta, Indonesia

Fitriyani, Iin; Wilian, Sudirman \& Yusra, Kamaludin. 2019. Ekspresi Bahasa Indonesia Tulis berdasarkan Gender pada Media Facebook.

Lingua (2019), 16(1): 137 156. DOI: 10.30957/lingua.v16i1.581.

bentuk asli dari status facebook yang diteliti. Teknik yang digunakan adalah melakukan screenshot atau tangkapan layar yaitu pengambilan gambar melalui handphone untuk merekam tampilan status yang berupa teks atau data-data yang diambil dari facebook untuk mencari data mengenai hal-hal yang berupa ungkapan perasaan atau curahan hati. Dimulai dengan menelaah, mengumpulkan seluruh data yang sudah terkumpul dari sumber yang akan diteliti di dalam status facebook.

Adapun metode analisis data adalah proses penyederhanaan data dan penyajian data dengan mengelompokkannya dalam suatu bentuk yang mudah dibaca dan diinterprestasi (Silalahi, 2012:332). Analisis data kualitatif dilakukan apabila data empiris yang diperoleh berupa kumpulan berwujud kata-kata dan bukan rangkaian angka serta tidak dapat disusun dalam kategori-kategori/struktur klasifikasi. Tahaptahap analisis data yang diadaptasi dari Miles dan Huberman (Silalahi, 2012:339) diuraikan sebagai berikut.

1. Identifikasi, yaitu melihat dan menentukan ciri objek kebahasaan berupa ekspresi bahasa berdasarkan gender dalam facebook.

2. Klasifikasi, pada tahap ini data-data status facebook yang telah dikumpulkan kemudian diklasifikasikan sesuai karakteristik bahasa laki-laki dan perempuan.

3. Penyajian, pada tahap ini data disajikan agar dapat memahami apa yang sedang terjadi dan apa yang harus dilakukan lebih jauh menganalisis ataukah mengambil tindakan berdasarkan atas pemahaman yang didapat dari penyajianpenyajian tersebut. Sehingga, akan terlihat keseluruhan data yang didapat sudah mencukupi dan sesuai dengan keinginan atau perlu dilakukan tindakan lagi.

4. Deskripsi, pada tahap ini data-data yang telah disajikan diuraikan secara jelas dan terperinci.

5. Eksplanasi/penjelasan, setelah diuraikan maka diberi penjelasan-penjelasan tentang keadaan sesuatu sebagai akibat dari sesuatu yang lain menggunakan bahasa yang mudah dimengerti.

6. Interpretasi, pada tahap ini menerangkan bahwa data-data yang telah dijelaskan tidak menurut apa adanya saja, melainkan diterapkan juga apa yang tersirat dengan mengutarakan pendapat sendiri.

7. Induksi/simpulan, pada tahap terakhir ini, menarik kesimpulan dan verifikasi. Makna-makna yang muncul dari data harus diuji kebenarannya, kekukuhannya dan kecocokannya, yakni yang merupakan validitasnya. Sehingga, simpulan ini akan menjawab rumusan masalah yang telah dirumuskan sejak awal.

Hasil analisis data dalam penelitian ini disajikan dengan menggunakan metode penyajian informal. Penyajian hasil analisis data secara informal adalah penyajian hasil analisis data dengan menggunakan kata-kata yang biasa (Sudaryanto, 1993: 145). Dalam penyajian ini, kaidah-kaidah disampaikan dengan kata-kata biasa, kata-kata yang apabila dibaca dengan serta merta dapat langsung dipahami. Kaidah itu berupa ekpresi bahasa yang terdapat dalam status facebook. 
LINGUA, Vol. 16, No. 1, Maret 2019

p ISSN: 1979 9411; e ISSN: 2442 238X

Http://lingua.pusatbahasa.or.id; Email:presslingua@gmail.com

Center of Language and Cultural Studies, Surakarta, Indonesia

Fitriyani, Iin; Wilian, Sudirman \& Yusra, Kamaludin. 2019. Ekspresi Bahasa Indonesia Tulis berdasarkan Gender pada Media Facebook.

Lingua (2019), 16(1): 137 156. DOI: 10.30957/lingua.v16i1.581.

\section{HASIL DAN BAHASAN}

\subsection{Jenis Ekspresi Facebooker dalam Status}

Hubungan bahasa dan gender, secara umum dapat dieksplorasi lewat perilaku bahasa dalam konteks sosial bagaimana laki-laki dan perempuan berkomunikasi dan berinteraksi. Tanpa disadari, penggunaan bahasa juga telah terpengaruh oleh adanya gender. Kata-kata yang berhubungan dengan laki-laki mempunyai banyak perbedaan makna dengan kata-kata yang dihubungkan dengan perempuan. Bahasa laki-laki itu berkonotasi pada kekuatan, kewibawaan atau kewenangan, atau status dan pencitraan yang bernilai positif, adapun kebanyakan bahasa perempuan berkonotasi pada seksual dan merendahkan diri yang pada akhirnya terkesan negatif. Ada temuan menarik yang dibahas pada pembahasan ini yaitu perbedaan pemilihan topik pembicaraan antara lakilaki dan perempuan dalam status facebook. Hasil dalam penelitian ini diperoleh 38 status facebook yang menjadi bagian dari tema-tema maskulinitas dan tema-tema feminitas. Tema-tema maskulin yang ditemukan dalam status facebook berjumlah 19 status seperti tampak pada tabel 3.

Tabel 3: bentuk maskulin dalam status facebookmenutur Tuncay

\begin{tabular}{|c|c|c|}
\hline No. & Topik Maskulin & Jumlah \\
\hline 1. & Kekuatan Fisik & 2 \\
\hline 2. & Altruisme & 1 \\
\hline 3. & Perempuan dan Seks & 2 \\
\hline 4. & Spiritualitas dan Moralitas & 4 \\
\hline 5. & Keluarga dan Cinta & 3 \\
\hline 6. & Kesenangan & 3 \\
\hline 7. & Kepemimpinan & 2 \\
\hline 8. & Aktivitas Outdoor & 2 \\
\hline \multicolumn{2}{|r|}{ Jumlah } & Total : 19 status \\
\hline
\end{tabular}

Tabel 3 menunjukan status facebook yang diunggah oleh facebooker laki-laki dan perempuan memiliki perbedaan tema/topik. Laki-laki cenderung mengunggah topik yang mencerminkan sisi maskulinitasnya. Dari data tema masklinitas Tuncay (2010), terlihat bahwa tema spiritual/moralitas merupakan tema yang paling banyak diunggah oleh facebooker laki-laki untuk menunjukkan sisi maskulinitasnya. Tema Keluarga dan kesenangan menjadi tema nomor dua yang sering diunggah oleh facebooker. Sedangkan temakekuatan fisik, perempuan, kepemimpinan dan kegiatan outdoor menjadi tema ketiga yang sering diunggah oleh facebooker laki-laki. Kemudian tema altruisme juga diunggah oleh laki-laki untuk menunjukkan sisi maskulinitasnya. Adapun tema-tema feminitas yang dipaparkan oleh Cholik (2016) dalam facebook ada 19 status facebook seperti tampak pada tabel 4. 
LINGUA, Vol. 16, No. 1, Maret 2019

p ISSN: 1979 9411; e ISSN: 2442 238X

Http://lingua.pusatbahasa.or.id; Email: presslingua@gmail.com

Center of Language and Cultural Studies, Surakarta, Indonesia

Fitriyani, Iin; Wilian, Sudirman \& Yusra, Kamaludin. 2019. Ekspresi Bahasa Indonesia Tulis berdasarkan Gender pada Media Facebook.

Lingua (2019), 16(1): 137 156. DOI: 10.30957/lingua.v16i1.581.

Tabel 4: bentuk feminim dalam status facebook menurut Cholik

\begin{tabular}{|l|l|c|}
\hline No. & \multicolumn{1}{|c|}{ Topik } & Jumlah \\
\hline 1. & Kuliner/memasak & 5 \\
\hline 2. & Kecantikan & 3 \\
\hline 3. & Fashion & 3 \\
\hline 4. & Parenting & 4 \\
\hline 5. & Traveling & 2 \\
\hline 6. & Hobi $\quad$ Jumlah & 2 \\
\hline \multicolumn{2}{|c|}{} \\
\hline
\end{tabular}

Perempuan cenderung mengunggah tema/topik yang mencerminkan sisi feminitasnya. Dari data tema feminitas Cholik (2016) topik kuliner/masak-memasak paling banyak diunggah oleh facebooker perempuan untuk menunjukkan sisi feminitasnya. Berdasarkan sistem patriarki, kodrat perempuan identik dengan dapur. Sedangkan, tema parenting cukup sering diunggah facebooker perempuan untuk memperlihatkan sisi kelembutan, kecintaan terhadap orang tua dan sisi keibuannya. Adapun fashion dan kecantikan menjadi tema/topik perempuan untuk menunjukkan sisi feminitasnya yang paling sering diunggah. Untuk tema fashion digunakan oleh perempuan sebagai ajang pamer barang-barang bermerk sebagai ajang bisnis jual beli online seperti baju dan tas. Sedangkan Traveling dan hobi juga menjadi topik yang paling diminati karena perempuan pada dasarnya lebih cepat penat dan stress dibanding laki-laki, serta suka mencari suasana baru yang alami. Sedangkan hobi perempuan yang ditemukan dalam observasi ini meliputi menanam dan make up.

\subsection{Perbedaan Ekspresi Menurut Gender}

Karakteristik kebahasaan pada status facebookyang diunggah oleh facebooker laki-laki dan perempuan memiliki perbedaan frekuensi penggunaan. Status facebooker laki-laki lebih cenderung mengunggah status yang sejalan dengan teori Coates (1986), dalam konteks ini meliputi swearing and taboo language, command and directive, dan impolite form "directness". Sedangkan facebooker perempuan lebih cenderung mengunggah status yang sejalan dengan teori Lakoff (1975) tentang fitur bahasa perempuan. Penggunaan karakteristik kebahasaan pada status facebook yang diunggah oleh facebooker dapat dilihat pada tabel 5.

Dalam beberapa data ditemukan terdapat beberapa karakteristik yang diungkapkan yaitu penggunaan kalimat langsung, kalimat tidak langsung, kalimat perintah, kalimat berita, dan kalimat tanya. 
LINGUA, Vol. 16, No. 1, Maret 2019

p ISSN: 1979 9411; e ISSN: 2442 238X

Http://lingua.pusatbahasa.or.id; Email:presslingua@gmail.com

Center of Language and Cultural Studies, Surakarta, Indonesia

Fitriyani, Iin; Wilian, Sudirman \& Yusra, Kamaludin. 2019. Ekspresi Bahasa Indonesia Tulis berdasarkan Gender pada Media Facebook.

Lingua (2019), 16(1): 137 156. DOI: 10.30957/lingua.v16i1.581.

Tabel 5: Karakteristik kebahasaan yang dikemukakan oleh Lakoff dan Coates pada status facebook

\begin{tabular}{|c|c|c|c|c|}
\hline \multirow{2}{*}{ No. } & \multirow{2}{*}{$\begin{array}{c}\text { Karakteristik } \\
\text { Kebahasaan }\end{array}$} & \multicolumn{2}{|c|}{ Jumlah dan persentase } & \multirow{2}{*}{ Keterangan } \\
\hline & & perempuan & Laki-laki & \\
\hline 1. & Empty adjective & $3(60 \%)$ & $2(40 \%)$ & $\begin{array}{l}\text { Contoh kata: keren, ngehits, anggun, } \\
\text { cantik, luar biasa. }\end{array}$ \\
\hline 2. & Hedges & $6(86 \%)$ & $1(14 \%)$ & $\begin{array}{l}\text { Contoh kata: sepertinya, masihkah, } \\
\text { mungkin, entah. }\end{array}$ \\
\hline 3. & Intensifier & $2(100 \%)$ & 0 & Contoh kata: sangat, benar-benar. \\
\hline 4. & Super polite form & $6(67 \%)$ & $3(33 \%)$ & Contoh kata: terima kasih, maaf, mohon. \\
\hline 5. & $\begin{array}{l}\text { Rising intonation on } \\
\text { declarativis }\end{array}$ & $5(83 \%)$ & $1(17 \%)$ & $\begin{array}{l}\text { Contoh kata: akankah, berlebihankah, } \\
\text { haruskah, benarkah. }\end{array}$ \\
\hline 6. & $\begin{array}{l}\text { Avoidance of strong } \\
\text { swear words }\end{array}$ & $4(100 \%)$ & 0 & $\begin{array}{l}\text { Contoh kata: menggunakan konotasi } \\
\text { halus, } 3 \text { diantaranya disampaikan secara } \\
\text { langsung, } 1 \text { diantaranya disampaikan } \\
\text { secara tidak langsung. }\end{array}$ \\
\hline 7. & Emphatic stress & $2(100 \%)$ & 0 & Contoh kata: benar banget, wow \\
\hline 8. & $\begin{array}{l}\text { Swearing and taboo } \\
\text { language }\end{array}$ & $2(29 \%)$ & $5(71 \%)$ & $\begin{array}{l}\text { Contoh kata: asu, tai anjing, haram jada, } \\
\text { anjing, bangsat, sok cakep. }\end{array}$ \\
\hline 9. & $\begin{array}{l}\text { Command and } \\
\text { directive }\end{array}$ & $1(17 \%)$ & $5(83 \%)$ & $\begin{array}{l}\text { Contoh kata: menggunakan imperatif } \\
\text { positif dan negatif secara halus dan } \\
\text { kasar. }\end{array}$ \\
\hline 10. & Impolite forms & 0 & $2(100 \%)$ & $\begin{array}{l}\text { Contoh kata: menggunakan bahasa } \\
\text { directness (terus terang) untuk } \\
\text { mengancam dan menyindir. }\end{array}$ \\
\hline & Jumlah & 31 & 19 & Total: 50 status \\
\hline
\end{tabular}

\section{Ekspresi dalam Status Facebook Perempuan}

Kutipan (1) terjadi ketika facebooker perempuan merasa tersinggung dengan penilaian orang lain terhadap dirinya. Orang lain tersebut menilai bagian fisiknya. Menurut facebooker hinaan fisik merupakan hinaan yang sangat sensitif bagi dirinya. Adapun komentar yang didapatkan dari perempuan yaitu P1 hanya memberikan komentar berupa emoji tertawa terhadap kejadian tersebut dan facebooker pun membalas dengan emoji tertawa. P2 memberi komentar dengan melampirkan UU jika ada orang yang menilai tentang fisik seseorang. Kemudian facebooker memberikan ucapan terima kasih. Kalimat berjenis kalimat langsung karena merupakan kejadian yang dialami oleh facebooker sendiri bukan kejadian yang dialami oleh orang lain.

(1) Status: paling benci kalau ada orang yang nggak gue kenal ngajak ngechat ujung ujung ngina gue pesek $*$ apaan si kalian ngehina fisik orang aja kerjaannya. Gue sensitif banget lo ga tahu kerasnya gue ngebangkit kepercayaan diri karena hinaan fisik dari kecil. Lo hidup kerjaannya Cuma nyinyir bentuk tubuh orang aja. Coba lo bikin sendiri manusia buatan lo sendiri kalau mampu. Kalau mahu cewek lo cantik sempurna kasih cewek lo uang buat operasi plastik sono.

Komentar:

P2: Dikasih itu aja mbak

FP: Hhhh iya ini yang kemarin ku lihat thanks say

P2: sami-sami mbak (:) 
LINGUA, Vol. 16, No. 1, Maret 2019

p ISSN: 1979 9411; e ISSN: 2442 238X

Http://lingua.pusatbahasa.or.id; Email: presslingua@gmail.com

Center of Language and Cultural Studies, Surakarta, Indonesia

Fitriyani, Iin; Wilian, Sudirman \& Yusra, Kamaludin. 2019. Ekspresi Bahasa Indonesia Tulis

berdasarkan Gender pada Media Facebook.

Lingua (2019), 16(1): 137 156. DOI: 10.30957/lingua.v16i1.581.

Konteks kutipan (2) terjadi ketika facebooker perempuan meminta tolong kepada temanfacebooknya karena kehilangan handphone. Konteks komentar berisi komentar perempuan yang mengira bahwa handphone tersebut sudah ditemukan. Facebooker membalas komentar tersebut bahwa bukan handphoneitu yang dimaksud melainkan handphone lain. Kemudian perempuan membalas komentar agar handphone tersebut cepat ditemukan. Konteks status berisi kalimat perintah tetapi disampaikan secara halus dan sopan oleh facebooker perempuan. Dalam konteks komentar juga berisi komentar yang santun dan sopan.

(2) Status: Tolong kasiaann yang lihat Hp ini atau yg temukan mohon di kembalikan ..

Hilang kemarin pagi.

Xiaomi Note 5 warna Hitam.

Tolong bantu share ..

Komentar:

P: sy kira kmrin sdh d dapat

FP: bkn hpx adeku itu.. Ad yg pux tafdi ambil

P: ohh smg cpt d dpt ksian

(3) Status: Kk tolong donk kerja samanya... Mangkanya kalo kep baju itu jangan nafsu

Lihat isi dompet dulu ya kak.. kami tdk memaksa anda membeli... tapi kalian tau kan aturan nya kan kalo kep berarti membeli.. jangan susah di hubungi.. wa di baca aja kyk koran... kalo satu.. ini lumaya lo.. untung yng titip barng juga tolong donk janjinya di tepati...

Gk ada kabar no di blokir,, tlfn di alihkan amksudnya apa hayo

Maaf kan sy ya kalo sy terpaksa buat postingan ini...

Ini karna kalian susah di hubungi

Komentar:

Kalo tdk php tolong selesai kan ya.. sy tunggu sampai sore ini

P: bnyk2 sabar kk hdpn orng kyk gtu

FP: iya kak

Konteks kutipan (3) terjadi ketika facebooker perempuan yang merupakan penjual online merasa kesal dengan pembeli yang sudah memesan barangnya tetapi tidak jadi membayar dan mengambil barang tersebut. Facebooker lantas merasa marah kepada pembeli tersebut tetapi tetap menggunakan bahasa yang halus dan sopan.

Konteks kutipan (4) berikut berisi kalimat perintah yang disampaikan secara sopan dan halus. Status berisi kata tolong yang merupakan imperatif positif. Konteks komentar berisi nasehat agar facebooker selalu sabar.

(4) Status: ketika orang lain sukses kamu punya rasa iri, sebal tandanya kamu punya penyakit

hati...

Buang jauh jauh pikiran seperti itu... karena akan mempengaruhi hasil kerjamu...

Fokus...

Berfikirlah... kalo kamu pasti bisa sukses seperti dia...

Tundukkan kepala,, dan baca astaghfirulloh hal'azim... dan tersenyumlah...

Komentar:

P: Kalo di arahkan ke hal positif bagus juga dek..

Jd iri yg positif, liat org sukses kita merasa tertantang Harus sukses juga 
LINGUA, Vol. 16, No. 1, Maret 2019

p ISSN: 1979 9411; e ISSN: 2442 238X

Http://lingua.pusatbahasa.or.id; Email: presslingua@gmail.com

Center of Language and Cultural Studies, Surakarta, Indonesia

Fitriyani, Iin; Wilian, Sudirman \& Yusra, Kamaludin. 2019. Ekspresi Bahasa Indonesia Tulis berdasarkan Gender pada Media Facebook.

Lingua (2019), 16(1): 137 156. DOI: 10.30957/lingua.v16i1.581.

FP: Seperti aku iri sama mu kak... tapi gak sebel juga, ikut seneng lah terus mikir kapan aku kayak gitu.. banyak x penolakan2 tapi ya kudu dijalani biar tau artinya berjuang..

Oh ternyata gini toh, kalo membangun dari awal.. aku selalu ingat kata2 mu kak. MALAS $=$ MATI $:$

Konteks data status (4) berisi nasehat dari facebooker perempuan kepada pembaca yaitu perintah untuk tidak merasa iri kepada kehidupan orang lain. Penyakit iri hati merupakan penyakit yang membuat hidup kita rugi seperti membuang waktu dan mempengaruhi hasil kerja. Facebooker juga mengajak pembaca untuk berfikir positif dan mengajak untuk selalu beristighfar dan tersenyum. Adapun komentar dari seorang perempuan yang memberikan masukan agar menggunakan rasa iri ke arah yang positif sebagai tolak ukur agar menjadi lebih baik juga. Kemudian facebooker membalas komentar dengan mengatakan bahwa dia iri terhadap kehidupan dari perempuan tersebut, tetapi iri secara baik. Berdasarkan konteks dapat disimpulkan bahwa data mengandung kalimat perintah yang diungkapkan secara langsung. Konteks komentar dibalas dengan kalimat langsung juga.

\section{Ekspresi dalam Status Facebook Perempuan dan Komentar Laki-laki}

Konteks kutipan (5) terjadi ketika facebooker perempuan menilai pada zaman sekarang lelaki lebih memilih fisik yang cantik daripada akhlak yang baik, sedang perempuan lebih memperjuangkan lelaki yang memiliki kekayaan daripada memperjuangkan seorang lelaki yang berjuang untuknya. Status mendapat komentar dari laki-laki. Laki-laki tersebut ragu-ragu untuk membenarkan penilaian dari status facebooker perempuan, sehingga facebooker membenarkan kalau zaman sekarang 80\% memang seperti itu adanya. Konteks status mengenai pendapat dari facebooker perempuan, konteks data termasuk kalimat langsung. Konteks komentar juga termasuk kalimat langsungdisampaikan secara jelas tidak bertele-tele.

(5) Status: Dan yg Cantik ahlakxa kala sma yg Cantik rupa,,, dan yg berjuang Kala sma yg beruang...

Komentar:

L: bisa jadi

FP: Bkn bsa jadi lgi tpi fakta

L: tapi masih bayak ko yg kebalikan y. positif aja dulu

FP: yg jls $80 \%$ yg sperti itu

(6) Status: aduh mantan2 kasian deh aku sama km mau manasin ak ama cewe kaya gitu aduh gak mempan ya baru penampilanya kaya gitu biar dia cantik bageikan bidadari pun aku gak sakit hati karna km dah bukan siapa2 aku lagi ok, jadi gak penting buat ak n gak ngurusin jangan jadi kan cewe lain jadi korban mu karna cinta kasian tau nih cewe

Komentar:

L: hadir

FP: makasi kaka ganteng

L: hehe tma tma adik cantik.... Cantik vs gantenk tar anak kita jdi apa ya

FP: ya kalau cantik pasti kaya bpknya kalau ganteng kaya ibunya opppsss kebalik ya hhhh 
L; haahhaa yayaya adik smga aj ank kita gk bnconk kalau bnconk kk gbukin pke spu msa bpak gntenk ankx bnconk

FP: hhhh oh tidak mungkin itu terjadi

Konteks data status kutipan (6) terjadi ketika facebooker perempuan merasa kesal terhadap mantan kekasihnya. Facebooker menyindir mantannya tetapi dengan cara yang sopan dan dalam kalimat terakhir juga berisi nasehat agar tidak menjadikan perempuan lain sebagai korban cintanya. Konteks status termasuk dalam kalimat langsung, karena tertuju untuk mantannya. Konteks dikomentari oleh laki-laki, tetapi tidak mengaitkan komentar dengan isi status facebook.

(7) Status: Jangan menyerah yaa

Komentar:

L: In Shaa Allah

FP: Aamiin

Konteks data status kutipan (7) berisi perintah agar tidak menyerah terhadap ujian yang terjadi dalam kehidupan. Konteks data berisi kalimat perintah yang disampaikan secara sopan oleh facebooker perempuan. Konteks komentar disampaikan dengan kalimat langsung oleh laki-laki dengan menjawabinshaa Allah, sehingga dibalas juga oleh facebooker dengan menjawab amin.

\section{Ekspresi Bahasa dalam Status Facebook Laki-laki dan Komentar Perempuan}

Konteks data status kutipan (8) terjadi ketika facebooker laki-laki memberikan nasehat kepada teman facebooknya agar tidak mengejar mantan. Status facebook sampaikan menggunakan guyonan seperti dalam kalimat biarkan dia mengejar kita. Dan disertai emoji senyum untuk mendukung guyonan tersebut. Status mendapat komentar dari perempuan yang meminta video yang terdapat dalam status facebook (8).

(8) Status: JANGAN PERNAH MENGEJAR MANTAN BIARKAN DIA MENGEJAR KITA (-) Komentar:

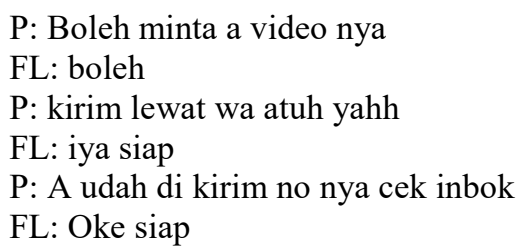

Konteks data kutipan (9) berisi kalimat perintah tetapi disampaikan secara sopan. Penggunaan kata tolong dalam kalimat termasuk imperatif positif yang berfungsi agar pembaca mengikuti keinginan facebooker. Konteks komentar juga ditanggapi oleh perempuan yang menggunakan bahasa yang sopan dan santun.

(9) Status: Jangan pernah ngejar orang yang udah ninggalin kita

Komentar:

P1: setuju banget 
LINGUA, Vol. 16, No. 1, Maret 2019

p ISSN: 1979 9411; e ISSN: 2442 238X

Http://lingua.pusatbahasa.or.id; Email: presslingua@gmail.com

Center of Language and Cultural Studies, Surakarta, Indonesia

Fitriyani, Iin; Wilian, Sudirman \& Yusra, Kamaludin. 2019. Ekspresi Bahasa Indonesia Tulis

berdasarkan Gender pada Media Facebook.

Lingua (2019), 16(1): 137 156. DOI: 10.30957/lingua.v16i1.581.

P2: bnerrr ngapain ngejar2 orang yg udah gak cinta n syang ma kita siiip

Konteks data status (9) menunjukkan facebooker laki-laki memberikan nasehat kepada pembaca agar tidak mengejar seseorang yang sudah meninggalkan kita. Status mendapat komentar dari perempuan. Mereka setuju dengan nasehat facebooker laki-laki tersebut. Status berisi kalimat perintah. Hal ini ditunjukkan oleh kata jangan yang merupakan salah satu kata yang digunakan dalam memerintah. Fungsi status ialah perintah yang disampaikan dilakukan oleh pembaca. Konteks komentar yang terdapat dalam status disampaikan secara langsung. Pada komentar P1 menyampaikan komentar secara jelas dan singkat, sedangkan pada komentar P2 menyampaikan komentar secara bertele-tele.

Konteks data status kutipann (10) terjadi ketika facebooker laki-laki menonton video yang berisi nasehat. Facebooker laki-laki juga memberikan nasehat dalam status facebooknya seperti nasehat dalam video tersebut. Status tersebut mendapatkan komentar dari perempuan yang meminta untuk dibagikan videonya.

Konteks termasuk kalimat perintah tetapi disampaikan oleh facebooker laki-laki dengan cara yang sopan. Konteks komentar dalam status berisi kalimat langsung yaitu ketika perempuan tersebut meminta video yang terdapat dalam status. Komentar berisi ekspresi bahasa yang sopan yang disampaikan baik oleh perempuan maupun dari facebooker laki-laki.

(10) Status: Hargai lah wanita Akhi

Jangan kau nodai dengan Nafsumu

Halalkan lah dia jika engaku ingin memilikinya

Komentar:

P: Assalamualaikum

Akhy mg ana boleh minta video nyh

FL: Waalaikumsalam langsung inbox ana aja yah

P: yh akhy mksih

Konteks data status kutipan (11) berisi nasehat agar tidak mengurusi kehidupan orang lain dan tidak menjelek-jelekkan kehidupan orang lain. Konteks data berisi kalimat perintah yang disampaikan oleh facebooker laki-laki dengan menggunakan bahasa yang sopan dan halus. Konteks komentar dari perempuan disampaikan secara langsung dan menyetujui nasehat tersebut.

(11) Status: gak usah nyinyirin hidup orang, enggak usah ncibirin keadaan orang, karena hidup yang kamu jalani sekarang ini juga belum tentu lebih baik dari dia.

Jangan suka nyinyirin hidup orang lain.

Setuju?

Komentar:

P: Betul, sebaik2nya manusia memiliki keterbatasan $\&$ tdk ada yg sempurna 
Konteks data status (11) terjadi ketika facebooker laki-laki sedang berada dalam bioskop tetapi masih menunggu terbukanya pintu ruangan bioskop tersebut. Konteks data pada status facebook berisi ragam bahasa yaitu bahasa daerah Sumbawa. Konteks data menggunakan kalimat langsung yaitu menanti dengan sabar terbukanya pintu bioskop. Adapun komentar dari seorang perempuan dalam status facebook menyuruh facebooker tersebut menanti sampai lelah. Kemudian facebooker menanggapi komentar tersebut dengan mengatakan mengerikan maksudnya adalah tidak mungkin menunggu pintu bioskop sampai lelah karena bioskop sudah memiliki jadwalnya dan memberitahukan kepada perempuan tersebut bahwa dirinya sedang menunggu terbukanya pintu di bioskop.

(12) Status: menanti dengan sabar dan penuh dengan keikhlasan...

Bismillah

Komentar:

P: Menantilah sampai lelah tuk mnanti

FL: merang pe. Tari buka lawang bioskop sak

(mengerikan. Menunggu terbukanya pintu bioskop ini)

Konteks (13) menjelaskan data status yang terjadi ketika facebooker membaca sebuah kejadian alam dari sebuah kelompok gempa bumi yang menganalisis tentang kejadian gempa bumi yang terjadi di seluruh dunia. Konteks data berisi kalimat berita. Status digunakan untuk memberitahukan kepada pembaca terhadap apa yang terjadi dalam permukaan tanah. Adapun konteks komentar yang dilakukan oleh perempuan yang mencoba untuk dijelaskan apa maksud dari status tersebut. Kemudian facebooker laki-laki meminta perempuan tersebut untuk membaca kembali keterangan yang ada dalam statusnya.

(13) Status: pembaruan sinar gamma (pelepasan dielektrik): beberapa paku besar telah mengenai ionosfer beberapa minggu terakhir saat monitor neutron Antartika merespons! A GLE: Peningkatan permukaan tanah aktif di sana pada tanggal 27 ! Induksi surya telah sangat rendah hari ini...

Komentar:

P: Ape maksud ne mas hero?

FL: :) keterangan di atas

Konteks data status kutipan (14) terjadi ketika facebooker laki-laki mengunggah gambar tentang bencana alam di Banten. Kejadian alam tentang terjadinya erupsi di Gunung Anak Krakatau. Kejadian tersebut diberitakan oleh facebooker laki-laki kepada teman-teman facebook. Adapun komentar dalam status ialah seorang perempuan yang langsung menrespon dengan mendoakan agar umat manusia diampuni oleh Allah. Komentar perempuan kedua mengungkapkan ekspresi sedang takut terhadap bencana yang sedang terjadi. Dapat disimpulkan bahwa konteks data berisi kalimat berita. Konteks komentar di atas berisi kalimat ajakan untuk berdoa agar umat manusia selamat dan mengekspresikan perasaan takut. 
LINGUA, Vol. 16, No. 1, Maret 2019

p ISSN: 1979 9411; e ISSN: 2442 238X

Http://lingua.pusatbahasa.or.id; Email: presslingua@gmail.com

Center of Language and Cultural Studies, Surakarta, Indonesia

Fitriyani, Iin; Wilian, Sudirman \& Yusra, Kamaludin. 2019. Ekspresi Bahasa Indonesia Tulis berdasarkan Gender pada Media Facebook.

Lingua (2019), 16(1): 137 156. DOI: 10.30957/lingua.v16i1.581.

(14) Status: Suasana terbaru Gunung Anak Krakatau, mohon doanya semoga selalu diberi keselamatan oleh Allah SWT. Aamiin.

\#PrayForBanten \#DoaKitaUntukBanten

\#PrayforSelatSunda

Komentar:

P1: Smoga Tuhan memberikan pengampunan dan kekuatan utk semua umat2nya.. amin

P2: Yaallah, takut ih ::

Konteks data status (1) berisi tentang facebooker lelaki yang bertanya kepada pembaca tentang potensi gempa di pulau Sumbawa. Facebooker laki-laki mencoba mencari jawaban dari potensi gempa selanjutnya apakah akan berkekuatan 7-7,4 M. Status dikomentari oleh perempuan yang meminta untuk tetap waspada. Kemudian terdapat juga komentar dari lelaki yang mempertanyakan maksud dari komentar perempuan tersebut. Perempuan itupun menjawab dengan langsung dan tegas. Berdasarkan konteks dapat disimpulkan bahwa konteks data berisi kalimat tanya dari facebooker laki-laki, struktur kata yang digunakan untuk bertanya merupakan struktur secara tegas dan to the point. Konteks komentar di atas mengandung kalimat ajakan untuk selalu waspada.

(15) Status: Apakah benar potensi gempa 7-7,4 M akan terjadi di Sumbawa krna menurut E \& W tanda* gempa kecil ttp terjadi di sekitar P.Sumbawa..Mohon Penjelasannya

Komentar:

P: Ttp waspada sj Sumbawa cz sdh trmasuk sasaran

L: sasaran apa? Kayak buronan aja

P: buronan gempa besar

\section{Ekspresi dalam Status Facebook Laki-laki dan Komentar Laki-laki}

Konteks data status kutipan (16) terjadi ketika facebooker laki-laki di sebuah restoran dengan foto hitam putih. Status berisi nasehat dari facebooker laki-laki tetapi diungkapkan secara tidak langsung agar pembaca melakukan apa yang diperintahkan yaitu ketika seseorang merasa dirinya berada pada saat terpuruk, maka orang tersebut akan mencoba melakukan hal positif yang bisa mengubah dirinya menjadi lebih baik. Konteks komentar berisi komentar dari laki-laki yang menanyakan tempat facebooker tersebut. Facebooker pun membalas komentar secara langsung dan tegas.

(16) Status: Semakin lama kau tinggal di kegelapan, semakin kau merindukan cahaya

Komentar:

L: Di mano tu pak, mantap lokasinyo, ajak2 sayo ko

FL: rumah makan simpang pakdo

Konteks data status kutipan (17) berisi kegiatan yang dilakukan oleh facebooker laki-laki dan temannya yaitu bertemu dengan salah satu ustad Indonesia yaitu Ustad Abdul Somad. Konteks data (17) termasuk kalimat langsung karena menceritakan apa 
LINGUA, Vol. 16, No. 1, Maret 2019

p ISSN: 1979 9411; e ISSN: 2442 238X

Http://lingua.pusatbahasa.or.id; Email:presslingua@gmail.com

Center of Language and Cultural Studies, Surakarta, Indonesia

Fitriyani, Iin; Wilian, Sudirman \& Yusra, Kamaludin. 2019. Ekspresi Bahasa Indonesia Tulis berdasarkan Gender pada Media Facebook.

Lingua (2019), 16(1): 137 156. DOI: 10.30957/lingua.v16i1.581.

yang terjadi saat itu dan dirasakan sendiri oleh facebooker laki-laki. Konteks status mendapat komentar dari laki-laki yaitu mengagumkan facebooker sebagai habib. Adapun komentar dari laki-laki lainnya yang mengatakan bahwa facebooker tersebut mirip dengan salah satu habib di Indonesia. Kemudian facebooker membalasnya dengan tertawa.

(17) Status: Hilang ngantuk habis ketemu ustad abdul somad

Komentar:

L1: Wah,, ada habib

FL: haahha

L2: Kembarannya habib bahar tu

\subsection{Klasifikasi Ekspresi Bahasa Berdasarkan Gender dalam Media Facebook}

Hasil analisis menunjukkan keseluruhan status berjumlah 105 status. Dari 105 status, 57 menggunakan emoticon sebanyak 166; 17 digunakan oleh facebooker lakilaki dengan jumlah 34 emoticon, dan 40 status diunggah oleh facebooker perempuan dengan 132 emoticon. Dilihat dari aspek keaktifan facebooker atau banyaknya status yang diunggah, menunjukkan perempuan lebih aktif dibanding laki-laki. Perempuan 57 status laki-laki 48 status. Ragam bahasa yang digunakan facebooker, beberapa menggunakan bahasa daerah dan bahasa asing. Periksa tabel 6 .

Tabel 6: keterkaitan tema/topik status yang diunggah dengan fitur bahasa yang digunakan

\begin{tabular}{|l|l|l|l|}
\hline \multirow{2}{*}{ No. } & \multicolumn{1}{|c|}{ Aspek } & \multicolumn{2}{|c|}{ Ekspresi Bahasa Berdasarkan Gender } \\
\cline { 3 - 4 } & $\begin{array}{l}\text { Struktur } \\
\text { kebahasaan }\end{array}$ & $\begin{array}{l}\text { Bahasa Maskulin } \\
\text { Cenderung menggunakan } \\
\text { struktur yang lengkap dan dapat } \\
\text { dipahami oleh pembaca, serta } \\
\text { bersifat argumentatif untuk } \\
\text { mengkritik kejanggalan di } \\
\text { sekitarnya }\end{array}$ & $\begin{array}{l}\text { Cenderung menggunakan struktur } \\
\text { bahasa yang panjang dan bertele- } \\
\text { tele, berfungsi untuk } \\
\text { mendeskripsikan sesuatu atau } \\
\text { menceritakan momen tertentu }\end{array}$ \\
\hline 2. & $\begin{array}{l}\text { Diksi/karakteri } \\
\text { stik } \\
\text { kebahasaan }\end{array}$ & $\begin{array}{l}\text { Cenderung menggunakan } \\
\text { bahasa yang directness (terus } \\
\text { terang), lugas, jelas, dan to } \\
\text { thepoint, serta karakteristik } \\
\text { command and directive }\end{array}$ & $\begin{array}{l}\text { Cenderung menggunakan bentuk } \\
\text { empty adjective, hedges, } \\
\text { internsifier, super polite form, dan } \\
\text { emphatic stress, juga sering } \\
\text { menggunakan kata sapaan untuk } \\
\text { menjalin keakraban }\end{array}$ \\
\hline 3. & Emoticon & $\begin{array}{l}\text { Tidak banyak menggunakan } \\
\text { emoticon }\end{array}$ & $\begin{array}{l}\text { Lebih banyak menggunakan } \\
\text { berbagai emoticon }\end{array}$ \\
\hline 4. & Ragam bahasa & $\begin{array}{l}\text { Lebih cenderung menggunakan } \\
\text { bahasa asing dan bahasa daerah }\end{array}$ & $\begin{array}{l}\text { Lebih cenderung menggunakan } \\
\text { bahasa Indonesia }\end{array}$ \\
\hline
\end{tabular}

\section{SIMPULAN DAN SARAN}

Penelitian ini menggunakan fitur bahasa status di media sosial sebagai objek penelitian. Penelitian ini menjabarkan bentuk ekspresi bahasa yang digunakan oleh lakilaki dan perempuan. Hasil penelitian menyimpulkan tiga hal. 
LINGUA, Vol. 16, No. 1, Maret 2019

p ISSN: 1979 9411; e ISSN: 2442 238X

Http://lingua.pusatbahasa.or.id; Email: presslingua@gmail.com

Center of Language and Cultural Studies, Surakarta, Indonesia

Fitriyani, Iin; Wilian, Sudirman \& Yusra, Kamaludin. 2019. Ekspresi Bahasa Indonesia Tulis berdasarkan Gender pada Media Facebook.

Lingua (2019), 16(1): 137 156. DOI: 10.30957/lingua.v16i1.581.

Pertama, status facebook, facebooker laki-laki dan perempuan memiliki perbedaan tema. Laki-laki cenderung mengunggah tema yang dikemukakan Tuncay (2006) untuk mencerminkan sisi maskulinitasnya, yaitu kekuatan fisik, altruisme, perempuan dan seks, spritualitas dan moralitas, keluarga dan cinta, kesenangan atau fun, kepemimpinan, serta kegiatan outdoor. Facebooker perempuan cenderung mengunggah tema yang dikemukakan Cholik (2016) untuk mencerminkan sisi feminitasnya, yaitu kuliner dan masak-memasak, kecantikan, fashion, parenting, traveling, dan hobi.

Kedua, Facebooker laki-laki maupun perempuan sama-sama menggunakan diksi/karakterteristik kebahasaan yang dikemukakan oleh Coates (1986) dan Lakoff (1975), namun frekuensi penggunaannya berbeda. Facebooker laki-laki cenderung mengunggah status yang sejalan dengan teori Coates, yaitu swearing and taboo language, command and directive, dan impolite form "directness". Adapun facebooker perempuan cenderung mengunggah status yang sejalan dengan teori karakterteristik kebahasaan Lakoff (1975) meliputi empty adjective, hedges, intensifier, superpolite form, rising intonation of declaratives, avoidance swear word, dan emphatic stress. Tidak ditemukan penggunaan tag question, hyper correct grammer, dan color words dalam tuturan tertulis seperti status yang diunggah facebooker laki-laki maupun perempuan.

Ketiga, diferensiasi gender yang tercermin dalam status facebook ini juga dapat ditinjau dari aspek penggunaan emoticon seperti " $;$, :D, :) " dst. Facebooker perempuan lebih banyak menggunakan emoticon dibandingkan facebooker laki-laki. Ditinjau dari aspek ragam bahasa yang digunakan yaitu bahasa daerah dan bahasa asing, facebookerlaki-laki lebih cenderung menggunakan bahasa daerah dan bahasa asing dalam mengunggah status dibandingkan facebookerperempuan. Dari aspek keaktifan facebooker atau banyaknya status yang diunggah, menunjukkan terdapat perbedaan jumlah antara laki-laki dan perempuan dalam menggunakan facebook. Perempuan cenderung mengunggah status lebih banyak dibandingkan laki-laki.

Penelitian tentang kaitan bahasa dan gender memang selalu menarik, khususnya tentang bahasa laki-laki dan perempuan. Pada penelitian ini objek data yang digunakan adalah status facebook yang diunggah oleh facebooker laki-laki maupun perempuan untuk memperlihatkan bentuk kebahasaannya. Tentunya penelitian serupa juga perlu dilakukan di media sosial lain, mungkin saja akan ditemui bentuk-bentuk relasi bahasa dengan gender yang baru bahasa di media sosial. Mengingat beragamnya media sosial yang saat ini trand dan berkembang di Indonesia, sehingga dapat menghasilkan pemaknaan atas bahasa maskulin dan bahasa feminis yang lebih beragam. Tema feminitas dan maskulinitas dalam penelitian ini memberikan saran kepada peneliti selanjutnya agar menggunakan teori lain sebagai pembanding sehingga akan menjadikan analisis semakin kuat.

\section{DAFTAR PUSTAKA}

Cholik, A. 2016. 7 Topik yang dapat Ditulis oleh Perempuan. Online (http://www.abdulcholik.com/tip-blogging/7-topik-ynag-dapat-ditulis-oleh-bloggerwanita). Diakses 14 Mei 2018 
Chulsum, Umidan Windy Novia.2014. Kamus Besar Bahasa Indonesia. Surabaya: Yoshiko Press.

Corrie. 2017. Teori Gender dalam Komunikasi. (online), (http://pakarkomunikasi:com/teori-gender-dalam-komunikasi-pengertiankonsep), diakses 7 Maret 2018.

Endriastuti, A. 2014. Konsep Maskulinitas Bonek Surabaya dalan Perspektif Budaya Arek. Tesis. Surabaya: FIB Universitas Airlangga.

Fakih, Mansour. 2006. Analisis Gender dan Transformasi Sosial. Yogyakarta: Pustaka Pelajar.

Keraf, Gorys. 2004. Komposisi: Sebuah Pengantar Kemahiran Bahasa. Flores: Nusa Indah.

Kridalaksana, Harimurti. 1985. Fungsi Bahasa dan Sikap Bahasa. Flores: Nusa Indah

Kuntjara, Esther. 2003. Gender, Bahasa, dan Kekuasaan. Jakarta: PT. BPK Gunung Mulia dan UK Petra Surabaya.

Lakoff, R. 1975. "Language and Women's Place". New York: Cambridge University Press. Online (http://Universalteacher.org.uk). Diakses 15 Mei 2018.

Mahsun. 2014. Metode Penelitian Bahasa. Jakarta: Rajawali Press.

Moleong, L. J. 2013. Metode Penelitian Kualitatif. Bandung: PT Remaja Rosdakarya.

Muhammad. 2011. Paradigma Kualitatif Penelitian Bahasa. Yogyakarta: Liebe Book Press.

Prakasa, J.S. 2015. Komunikasi dan Gender: Perbandingan Gaya Komunikasi dalam Budaya Maskulin dan Feminim. Jurnal Ilmu Politik dan Komunikasi. 5 (1): 1-19.

Shaevitz, Marjonrie Hansen. 1989. Wanita Super. Terjemahan dari buku asli "The Superwomen Syndrome". 1984. Alih Bahasa Agus Santoso. Yogyakarta: Kanisius.

Silalahi, Ulber. 2012. Metode Penelitian Sosial. Bandung: Reflika.

Sudaryanto. 1993. Metode dan Aneka Teknik Analisis Bahasa (Pengantar Penelitian Wahana Kebudayaan Secara Linguistis). Yogyakarta: Duta Wacara University Press. 
LINGUA, Vol. 16, No. 1, Maret 2019

p ISSN: 1979 9411; e ISSN: 2442 238X

Http://lingua.pusatbahasa.or.id; Email: presslingua@gmail.com

Center of Language and Cultural Studies, Surakarta, Indonesia

Fitriyani, Iin; Wilian, Sudirman \& Yusra, Kamaludin. 2019. Ekspresi Bahasa Indonesia Tulis berdasarkan Gender pada Media Facebook.

Lingua (2019), 16(1): 137 156. DOI: 10.30957/lingua.v16i1.581. 